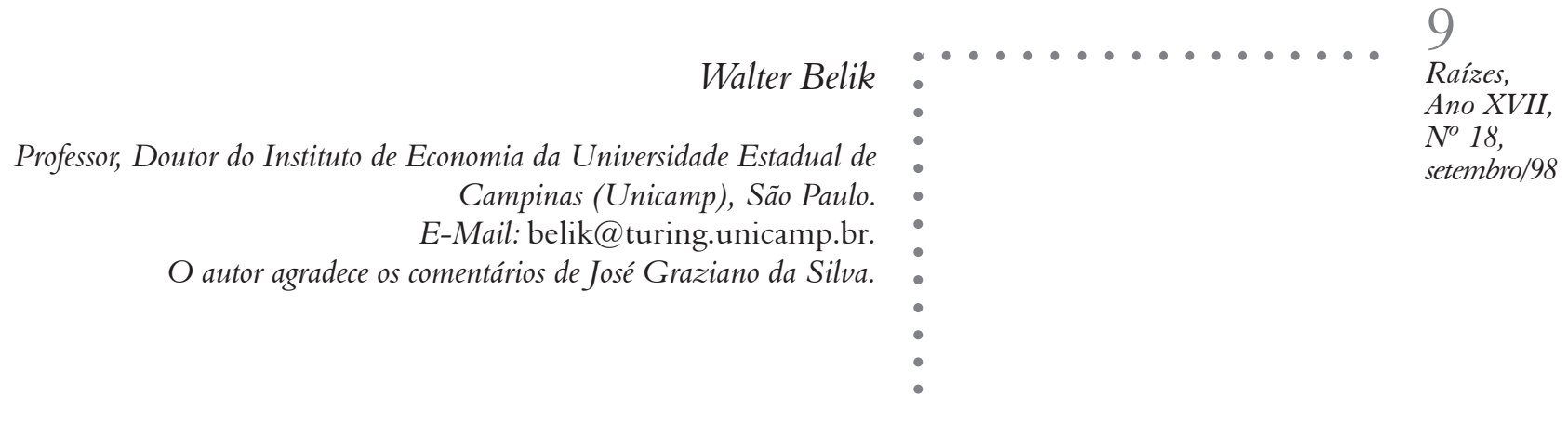

\title{
Mudanças no Padrão de Intervenção do Estado no Complexo Agro-industrial Brasileiro
}

As recentes transformações ocorridas na gestão da política agrícola não podem ser atribuídas unicamente ao esgotamento dos instrumentos de financiamento do setor rural instituídos há 30 anos. Na realidade, a gestão das políticas públicas no Brasil está entrando em uma nova fase. Este trabalho tem como objetivo demonstrar que as formas de regulação vigentes durante toda a fase de modernização da agricultura e formação dos Complexos Agroindustriais não podem mais ser encontradas no momento atual. Ou seja, a forma de se "fazer política agrícola" no Brasil mudou. Com isto, deve-se buscar também um novo referencial para analisarmos as condições concretas para a resolução dos recorrentes problemas do campo.

Durante os últimos 30 anos, a agropecuária brasileira sofreu um processo de modernização acele- rada com o conseqüente crescimento da produção, ocupação de novos espaços e atendimento de novos mercados. A economia brasileira entra nos anos $90 \mathrm{em}$ um contexto bastante distante daquele observado quando da instituição dos tradicionais instrumentos de política agrícola. Dois elementos fundamentais no planejamento de políticas agropecuárias, que não estavam presentes nos anos 60 , se colocam no momento, a saber: o colapso das fontes de financiamento público e a integração acelerada de mercados com a queda das barreiras comerciais.

O presente artigo analisa as mudanças ocorridas na Política Agrícola no Brasil nos últimos anos e as novas formas de intervenção nos mercados a partir do início da década. A hipótese que estaremos colocando é que a regulação do setor agrícola e agro-industrial passou por três fases sucessivas nos últimos trinta anos, a saber:

Em uma primeira fase, delimitada pelas reformas de 1964 e que vai até o final dos anos 70, há uma forte presença do Estado que passa a determinar o crescimento do setor agrícola e a sua articulação com os setores à montante e à jusante da agropecuária. Neste primeiro período, ocorre uma "fúria regulatória" em que os diversos governos passam a disciplinar praticamente todos os aspectos da política agrícola. Aos instrumentos clássicos de política agrícola, como o crédito, preços mínimos, seguro, assistência técnica, etc., acrescentam-se instrumentos de apoio à exportação, abastecimento interno e armazenagem, além de outros aspectos específicos para cada Complexo Agro-industrial (CAI).

Em segunda fase, que se inicia nos primeiros anos da década de 
80, motivada pela redução nos subsídios implícitos no crédito e pela pretensa "maturidade" do setor agrícola, alguns CAIs entram em uma fase muito próxima da autoregulação, no seu sentido clássico. A auto-regulação se dá na gestão das formas de financiamento do setor, que se diversificam e se ampliam, e na criação de sistemas de apoio, classificação e integração com os mercados. Neste caso, o que vai ocorrer é o fortalecimento de atores e instituições privadas ao mesmo tempo que o aparato público de ação junto a agricultura e agropecuária se retrai. Na medida em que as decisões de políticas começam a percorrer outros caminhos, passando ao largo do Estado, temos uma maior autonomia dos interesses constituídos em torno dos diferentes CAIs.

Em uma terceira fase, que se inicia ao final dos anos 90 , vai ocorrer um verdadeiro desmonte das instituições e instrumentos que nortearam a Política Agrícola e Agro-industrial desde a criação do SNCR. Os volumes de crédito voltados ao segmento agropecuário chegam aos seus níveis mais reduzidos. Da mesma maneira, as arenas regulatórias tradicionais são desativadas. Estas mudanças ocorrem em um período de abertura comercial acelerada e integração regional, afetando mais diretamente o segmento agropecuário e agroindustrial. O que ocorre nesta fase então é uma tendência à desregulação. Na ausência de uma agenda mínima de atuação e vivenci- ando conflitos internos quase que insuperáveis, a agropecuária e agroindústria mergulham em um intenso processo de reestruturação. As vantagens competitivas anteriores - naturais ou criadas pelas políticas de governo - dão lugar a uma situação instável e com baixas perspectivas de planejamento de longo prazo.

Ainda é cedo para que se possa determinar as perspectivas futuras dos diferentes CAIs no contexto da agropecuária brasileira. É certo de que desta reestruturação deverão emergir novas relações entre os diferentes atores e o Estado. Dentro da cadeia produtiva, novas relações de poder estão se produzindo. Em resumo, os interesses constituídos estão se alterando motivando um repensar das práticas e políticas a serem adotadas pela agricultura e agroindústria.

\section{I - Grupos de Interesses e Po- líticas Públicas}

A modernização da agricultura e o desenvolvimento da agroindústria processadora no Brasil podem ser vistas como um processo de dupla mão envolvendo o Estado e os grupos de interesses organizados. Por um lado, determinados interesses organizados pressionam o Estado obtendo programas e recursos para o seu desenvolvimento. Na outra mão, o Estado, através de suas políticas de governo, constitui lideranças, que por sua vez dão origem aos interesses organizados setorialmente. Este mecanismo de governança difere em muito dos usuais mecanismos “de mercado”, que não se aplicam para o entendimento de políticas públicas, principalmente em países de capitalismo retardatário e com profunda tradição burocrático-autoritária.

Com efeito, a constituição e organização das políticas no capitalismo monopolista pressupõe alguma forma de concertação entre os diferentes grupos de interesses, inclusive aqueles interesses autênticos concretizados no corpo do Estado, como os interesses de Governo e dos tecnocratas. Em outras palavras, o capitalismo monopolista pode ser tratado como uma forma organizada de desenvolvimento econômico diferentemente das interpretações tradicionais do "mercado", em que os agentes trocam ativos de maneira fortuita e isolada.

É no marco da abordagem neocorporatista que encontramos o melhor instrumental para o entendimento deste período de intensa regulação por parte do Estado. O que nos atrai para a teoria neocorporatista é a própria dificuldade empírica dos paradigmas que procuram explicar a relação entre Estado e Sociedade1. O neocorporatismo é um termo cunhado em português à semelhança do "corporatism" em inglês, o que nos permite diferenciá-lo do corporativismo enquanto regime de esta- 
do vigente no Brasil e outros países no período pós-guerra. O corporatismo é um sistema de representação de interesses em que as decisões são tomadas sob consenso. Não se tratam de interesses nus, mas interesses constituídos em torno de demandas específicas. Para diferenciar esta organização de interesses das antigas corporações da Idade Média, denominamos este sistema de neocorporatista, ou seja, um novo corporatismo ${ }^{2}$.

Segundo Cawson (1985: 8) "o corporatismo é um processo sóciopolítico específico no qual as organizações, representando os interesses monopolísticos funcionais se engajam em uma troca política com agências do Estado visando benefícios de política pública, que envolvam estas organizações no papel que combine". representação de interesses e implementação política através de auto-observância delegada”. Schmitter (1985) distingue três tipos de corporatismo, dependendo da maior ou menor força do Estado e da coesão dos grupos econômicos envolvidos.

Um primeiro tipo de corporatismo é chamado de governo privatizado e se caracteriza pela privatização de organismos de Estado por parte de representações monopolistas com o objetivo de obter subsídios ou criar normas restritivas a emergência de novos sistemas organizados. Um segundo tipo é definido por Schmitter como aquele em que "o Estado-normalmente sob um mandato autoritário - cria, coopta ou controla uma organização de interesses e pode, para tanto, coagir os seus líderes ou membros" (1985:60). A este segundo tipo Schmitter deu o nome de governo subordinado. Finalmente, temos um terceiro tipo de organização da sociedade denominado de governo de interesse privado (GIP). $\mathrm{O}$ GIP existe quando o Estado não tem condições de controlar, em regime de monopólio, os arranjos da produção e distribuição de bens e serviços. Por outro lado, o Estado no GIP tem condições de exercer influência sobre as condutas, impondo determinadas regras de coexistência. O resultado deste processo é uma alta dose de autoregulação por parte das organizações.

No caso mais concreto do processo de modernização da agricultura e constituição dos Complexos Agro-industriais no Brasil, o que nos interessa mais de perto são as modalidades de "governo subordinado" e de "GIP". Para o "governo subordinado", Schmitter (1985) recorda que esta é uma característica encontrada com muita freqüência, algum tempo atrás, na América Latina e Europa Meridional.

No Brasil, a importância de um projeto de desenvolvimento traçada desde o Período Vargas levou a que se "criasse" legitimidade para determinados grupos de interesses. $\mathrm{Na}$ falta destes interesses estarem organizados, o Estado reconhecia o "status" de interlocutor a determinadas organizações com maior influência, em torno da qual iriam gravitar os interesses ainda desorganizados ${ }^{3}$. Desta forma, foram "criadas" as diferentes formas de representação de interesses com a concorrência e sob o patrocínio do próprio Estado. A chave para o entendimento deste período está na força política ou de alavancagem de recursos em mãos do Estado.

A partir do início dos anos 80 , com a emancipação de determinados grupos de interesses e também com a crise política dos governos e crise fiscal do Estado, vai ocorrer uma mudança qualitativa nas formas de regulação e organização dos interesses constituídos. Destaca Streeck e Schmitter (1985: 20) que as agências governamentais estão sempre preparadas para aceitar a auto-regulação "voluntária" mesmo que isto implique em concessões e perda de controle direto. Neste caso, aquilo que o Estado perde acaba sendo recuperado com menores custos de implementação e maior efetividade. O GIP pressupõe um Estado com um certo grau de autonomia e força para fazer com que determinados custos de manutenção das políticas setoriais sejam devidamente incor-

- ${ }^{3}$ Claus Offe (1989) lembra que o funcionamento de um sistema corporatista pode estar ligado ao

- grau de atribuição de "status" por parte do governo a instituições privadas. Existem quatro formas

- de atribuição de "status", a saber: 1) recursos; 2) representação; 3) organização (regulação das rela- ções internas) e 4) procedimento (grau de possibilidade de licenciamento).
} 
porados pelas organizações. Por outro lado, este Estado deve ser fraco o suficiente para ter que governar com a concorrência dos interesses privados organizados.

O colamento entre o ambiente de definição das políticas no início dos anos 80 e as características do GIP é um dado concreto. É a partir do início dos anos 80 no Brasil que os interesses setoriais sofrem um verdadeiro processo de emancipação passando a definir de forma autônoma, ainda que contando com a supervisão do Estado, os principais elementos para o desenvolvimento de uma política setorial. Em que pese a ênfase mais geral da política econômica colocada no controle de preços, cabia aos interesses organizados definir aspectos como margens, classificação e diferenciação de produtos, mudanças de tabelas de preços, etc. Por sua vez, o Estado tinha maior poder de barganha com relação a aspectos como a carga tributária, nível de preços e nível de oferta interna.

É curioso que para o caso britânico podemos observar o mesmo movimento transitando de um "governo subordinado" para um "governo de interesses privados" na década de 70. Cox, Lowe e Winter (1986), que estudaram a emergência dos interesses privados no agro britânico representados pela NFU - National Farmer Union mostram que no início "os contro- les formais e os arranjos burocráticos eram necessários. Isto ocorreu parcialmente devido às emergências de guerra mas também porque os governos tinham ainda que desenvolver uma capacidade gerencial para administrar o setor agricola e a NFU ainda não tinha alcançado capacidade efetiva de gerenciar a sua própria constituição" (1986:488). Mais adiante, os autores afirmam: "o corporatismo no setor agrícola trocou sua ênfase de uma espécie de intervenção do Estado para uma complexa parceria envolvendo um alto grau de auto-regulação" (idem, ibidem $)^{4}$.

O corporatismo faz parte do jogo pós-liberal. Este sistema de governança é policêntrico, em que as instâncias de decisão são repartidas em fóruns específicos com representação tripartite: Capital, Trabalho e Poder Público. Porém, é ao nível da gestão das políticas setoriais que envolvem a agricultura que nos interessa mais de perto a atuação deste conjunto de interesses. Ou seja, é no âmbito destas instâncias decisórias extra-mercado que se colocam as principais variáveis para o entendimento da política agrícola do período.

Não se trata, portanto, de ver a política pública governada pela ação dos "lobbies", mas sim o legítimo jogo de interesses atuantes em um contexto em que o governo exerce a seletividade na distribuição de recursos e benefícios. $\mathrm{O}$ resultado deste formato de política agrícola permitiu a constituição, desenvolvimento e fortalecimento de alguns importantes CAIs da economia brasileira. Não se trata apenas da organização de convenções entre os agentes através de um sistema de contratos (explícitos ou implícitos), mas sim de um completo sistema de regulação mesoeconômico ou setorial.

Neste sistema atuam as organizações, atendendo especificamente as demandas dos representados e as instituições "que são as instâncias sobre as quais os indivíduos não atuam diretamente mas editam as regras ou administram dispositivos no seio das quais os indivíduos se coordenam" ${ }^{5}$. Assim, mais do que a ação dos lobbies, os diferentes benefícios obtidos pelas organizações refletiram a articulação e o envolvimento dos grupos e do Estado na manutenção das políticas. Para resumir, podemos afirmar que a formação e consolidação dos Complexos Agro-industriais são o resultado da constituição de uma estrutura de organização e representação de interesses e suas relações com o Estado. Como demonstraram Belik (1992), Soto (1992) e Ramalho (1994), os interesses setoriais fornecem a "liga" para a constituição dos CAIs, reforçando a necessidade teórica de entender as organizações e o processo de representação de seus interesses ao nível meso.

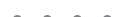

- ${ }^{4}$ Esta transição pode ser identificada ocorrendo entre as décadas de 70 e 80 devido a um maior

- envolvimento das organizações e também devido a uma mudança de conjuntura decorrente da en-

trada da Grã-Bretanha no Mercado Comum Europeu.

- ${ }^{5}$ Ver a este respeito Brousseau (1996). 
Bertrand (1982) talvez tenha sido o primeiro autor a chamar a atenção para o fato de que os complexos são verdadeiras frentes de interesses organizados. Portanto, enquanto frentes orquestradas, eles não podem ser tratados como um simples nível de agregação de cifras e participações à semelhança dos estudos de economia industrial.

Em uma primeira fase da política agrícola brasileira, denominada aqui de regulação estatal, o Estado molda os interesses privados segundo as suas necessidades de desenvolvimento e soberania. $\mathrm{O}$ Estado emancipa interesses através da participação na sua organização e consolida parcerias na implementação de políticas setoriais. Neste caso, vale a observação de Cawson de que "certos tipos de organização foram desenvolvidas sob um caráter semi-compulsório, suas restrições e disciplina dos seus membros fazem com que geralmente seja impossível ou muito difícil sair da organização. É muito comum que esta capacidade de controle social possa promover ou ser licenciada pelo Estado, e usada como meio para implementar políticas públicas" (Cawson, 1985:4). Como se observa, as organizações corporatistas não apenas representam as categorias como também jogam um papel importante na governança.

Os fatores que influenciam a relação entre Estado e interesses privados nas diferentes formas de governança serão analisados em seguida, identificando-se os elementos de influência na gestão das políticas agropecuárias no Brasil. O que pretendemos mostrar é que há um colamento entre a mudança das condições macroeconômicas e as formas de governança, e que esta mudança está ligada às transformações ocorridas nas relações entre os grupos de interesses constituídos e o Estado.

\section{II - A Gestão Dirigida da Política Pública e a Moderni- zação Compulsória}

As reformas ocorridas após o golpe de 1964 tiveram impacto direto no setor rural. Até meados dos anos 50 , havia um consenso entre os formuladores de política de que a agricultura "não representava um entrave para o desenvolvimento econômico" uma vez que esta cumpria suas funções de prover alimentos e mão-de-obra para a economia urbana florescente ${ }^{6}$. No entanto, diante da alta do preço dos alimentos e das crescentes pressões exercidas pelos movimentos sociais no campo, muda o enfoque dado ao agro que passa a ser considerado um setor "atrasado" ou "retardatário". Diante deste diagnóstico, o governo militar coloca em marcha a montagem de um estrutura completa de modernização para o setor.
A partir da constituição do Sistema Nacional de Crédito Rural em 1965, o setor agropecuário passa a contar com fundos permanentes destinados ao financiamento das atividades agropecuárias. Estes fundos tinham como fontes: a) as exigibilidades bancárias sobre os depósitos à vista dos correntistas; b) empréstimos externos e c) recursos do orçamento fiscal da União. A sua destinação principal eram as atividades agropecuárias, mas estes fundos eram vinculados à utilização de insumos e equipamento moderno. O impacto desta política foi imediato. Para se ter uma idéia da abrangência das mudanças ocorridas, basta dizer que, entre 1960 e 1980, a relação entre hectares cultivados e tratores diminuiu sete vezes. Já na década de 70, o país ostentava o título de " $2^{\circ}$. mercado para tratores e $2^{\circ}$. parque de produção" (Pinto, 1981:23).

No final dos anos 70 , o estoque de tratores em poder dos agricultores era próximo de 400.000 unidades com mais de $10 \mathrm{HP}$ (World Bank, 1982: 63), refletindo o crescimento da demanda e a bem sucedida política de incentivos que financiava o agricultor a taxas negativas e pagava a indústria fornecedora à vista. $\mathrm{O}$ mesmo se deu com a absorção de fertilizantes e defensivos, que foram diretamente afetadas por uma política de substituição de importações acelerada.

- ${ }^{6}$ Costuma-se estabelecer cinco funções básicas para a agricultura: 1) produção de alimentos e maté-

- rias-primas; 2) ampliação e disponibilidade de divisas; 3) transferência de mão de obra para outros

- setores; 4) fornecimento de recursos para outros setores e 5) expansão do mercado interno (Confor-

- me Accarini, 1987). Ver também a este respeito Mueller (1982).
} 
Juntamente com o Crédito Rural público, o governo lança o $\mathrm{PRO}-$ AGRO - Programa de Seguro Rural a fim de garantir os créditos dos bancos aos agricultores em 1973. Outros mecanismos de apoio oficial ao SNCR surgem também no início da década de 70 com a criação da EMBRAPA e da EMBRATER, para cuidar, respectivamente, da pesquisa e da assistência técnica oficial. A adoção de tecnologias modernas vinculadas a um pacote tecnológico pré-determinado era costurado pelas amarras do seguro rural, assistência técnica e adaptação tecnológica. Em seguida, ocorre uma maior diversificação das oportunidades de crédito com a ampliação da Política de Garantia para os Preços Mínimos para diversos produtos agrícolas e agroindustriais.

Do lado do escoamento da produção, a presença do Estado foi também marcante. A intervenção do Estado através de estoques reguladores e a ação direta junto aos mercados já estavam presentes na década de 40, mas tinham como base o esforço de acomodar as demandas do consumo a uma economia de guerra ${ }^{7}$. No que se refere a ponta do consumo, a criatividade dos governos deu origem a intervenção no mercado doméstico através de entrepostos para atacadistas e até mesmo supermercados para a venda no varejo de gêneros alimentícios para as populações carentes. Na década de 60 , estas ações se amplificam com a criação da Cibrazém -Companhia Brasileira de Armazenagem -, a Cobal - Companhia Brasileira de Alimentação - e mais tarde, dos CEASAs e Rede SOMAR nos governos militares.

Pelo lado da indústria processadora, as políticas implementadas após o golpe de 1964 permitiram construir um enorme feixe de financiamentos, tendo como base recursos orçamentários e do crédito rural, administrados pelo Banco do Brasil, Banco Central e BNDES. A principal origem destes créditos estava na conta FUNAGRI - administrada pelo Banco Central - que tinha como fonte de recursos o volume de exibilidades não utilizado pelo crédito rural. Este volume de recursos, que alcançou em determinados anos uma terça parte do crédito rural disponibilizado pelo SNCR, era engrossado também por recursos obtidos junto ao Tesouro Nacional que se destinavam a programas específicos de desenvolvimento agroindustrial, como o Programa Nacional do Álcool e os diversos Planos Nacionais de Celulose e Papel, para ficarmos em apenas dois exemplos $^{8}$.

$\mathrm{Na}$ frente externa, a intervenção do Estado se dava de modo pontual com ação direta de "tradings" estatais, como era o caso do café e do açúcar; ou de forma genérica: atuando através da taxa de câmbio, isenções, "rebates" e créditos-prêmio.

Como se observa, as ações desencadeadas a partir de 1964 para o campo levavam a uma mudança qualitativa no papel da agricultura. Segundo Graziano da Silva, "já vai de longe o tempo em que se pregava que a agricultura brasileira, depositária de uma estrutura de posse da terra herdada dos tempos coloniais, seria um obstáculo ao processo de formação de um capitalismo industrial no país, seja pela rigidez da oferta de alimentos, seja pela retenção da mão de obra, seja pela não expansão do mercado interno: o chamado milagre brasileiro se encarregou de destruir este mito" (1982:27). No Brasil, diante deste grande pacote de financiamentos e incentivos, após um curto período, temos uma parcela significativa da agricultura modernizada.

Torna-se desnecessário aprofundarmos mais os efeitos destas mudanças, lembrando apenas que o processo de modernização da agricultura trouxe mais concentração fundiária e de renda, incentivo a monocultura e destruição do meio ambiente. Como elemento importante desta primeira fase de modernização induzida, podemos destacar que a política agrícola havia sido desenhada por região e por produto e não por tipo de produtor, o que nos leva a considerar a im-

- ${ }^{7}$ Linhares, M.Y.L. (1979). Ver a este respeito a ação do SAPS - Serviço de Assistência da Previdência

- Social -, da Coordenação da Mobilização Econômica da Comissão Nacional de Alimentação e tam-

bém da CFP - Comissão de Financiamento da Produção .

- ${ }^{8}$ Em relação a estes aspectos, ver Belik (1992). 
portância dos interesses organizados em torno das cadeias produtivas.

Um indicador genérico para a importância atribuída e para o crescimento do setor agrícola está no volume oficial de crédito rural. Tomando-se os valores em dólares correntes, verifica-se que o montante oficial de crédito rural salta de um patamar de US\$ 6 a 7 bilhões no início da década de 70 para um volume em torno de US\$ 25 bilhões ano em meados desta década. Como vimos, o crédito rural contava com um sistema permanente de captação - baseado nas exibilidades, recursos do Tesouro e empréstimos externos - que até meados dos anos 70 não estava sujeito a grandes crises. De fato, a exibilidade bancária sobre os depósitos à vista se mantém elevada, dado que, com a inflação abaixo dos 50\% a.a., o volume de depósitos à vista ainda se mantém nos mesmos patamares. Por outro lado, não haviam muitas restrições a utilização de recursos do orçamento monetário para o financiamento da atividade rural, seja porque o controle sobre o déficit público era precário ou seja porque a captação de recursos externos se fazia a taxas relativamente reduzidas. Como pode ser observado no levantamento realizado por Werner Baer (1995:153), os empréstimos do Banco do Brasil eram os principais fatores de expansão da Base Monetária, sendo que os empréstimos do setor rural representavam algo em torno de $60 \%$ deste total durante os anos 70 .
As estatísticas de crédito rural recolhidas por Pinto (1981) nos mostram que o crédito agrícola como um todo cresceu em torno de $850 \%$ entre 1968 e 1978, já o número total de contratos apenas foi multiplicado por 3,5 vezes, fazendo com que o valor médio se elevasse em mais de $170 \%$, em termos reais. Em termos de distribuição do crédito, o Censo de 1980 aponta que $80 \%$ dos estabelecimentos agrícolas não recebiam qualquer crédito, mas que apenas $1 \%$ dos estabelecimentos, que produziam $15 \%$ do total e empregavam $3 \%$ da mão de obra, receberam $40 \%$ dos recursos. Considerando-se que os incentivos voltados a agropecuária não eram apenas de crédito, mas também garantia de aquisições ou empréstimos, tomando como base o preço mínimo, isenção de impostos para exportação e créditos à agroindústria, verifica-se que este segmento pode ser considerado privilegiado.
O Gráfico 1 apresenta a evolução do crédito rural nos últimos 26 anos, convertidos em dólares constantes de 1995. Neste, observamos que o período de maior volume de crédito para a agricultura ocorreu em meados da década de 70. Em termos constantes, o crédito oficial obtido pelos agricultores nos anos de 1974 ou 1975 foi de aproximadamente seis vezes aquele fornecido no ano de 1995. Vale lembrar que a produção de grãos mal ultrapassava 40 milhões de toneladas até 1979 , atingindo mais de 70 milhões em 1995. O gráfico ilustra um período de verdadeira gestão sob o controle público dos principais elementos da política agropecuária, que tinham como eixo articulador o crédito rural.

Do ponto de vista macroeconômico, as condições de expansão da modernização no interior dos CAIs se viram favorecidas pela manutenção do câmbio favorável. Após as maxidesvalori-

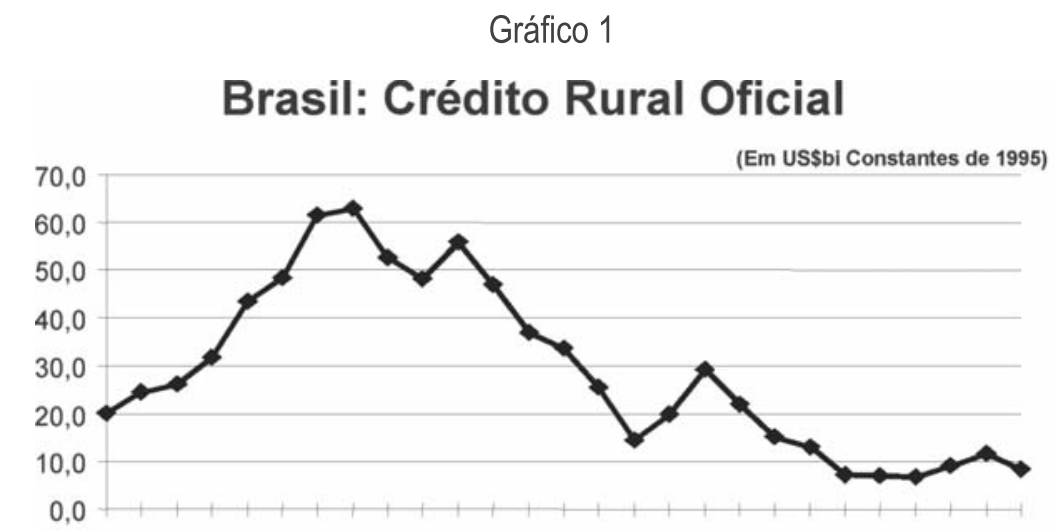

19691971197319751977197919811983198519871989199119931995 Fonte dos Dados Brutos: FAO, 1992 
zações de 1979 e 1983, a taxa de câmbio na década de 80 se mantém relativamente depreciada. Tomando-se os estudos desenvolvidos pela FAO sobre o desempenho da agropecuária brasileira nos anos 80 , observa-se que “no período 1981-84 todas as políticas macroeconômicas e setoriais foram orientadas para o reestabelecimento do equilíbrio externo de curto prazo através da geração de mega-superávits na Balança Comercial" (FAO,1992: 85).

Segundo Goldin e Castro de Rezende (1993), a manutenção do câmbio desvalorizado impulsionou as exportações agrícolas, além de baratear os insumos para a sua produção. Por outro lado, a política de "exportação à qualquer custo" tornou os estoques internos inexistentes, uma vez que os preços externos eram mais compensadores que os internos ${ }^{9}$. Procurava-se, com isto, incentivar as exportações, mas o resultado final terminou por elevar o montante dos juros e da dívida dos governos, o que aprofundava ainda mais o desequilíbrio externo do país. Ademais, ao desvalorizar a moeda, a fim de favorecer a agricultura como um todo, penalizava-se o consumidor interno com preços mais elevados. Para a agricultura, a política proporcionou enormes ganhos aos exportadores que passa- ram a se financiar junto aos fornecedores ou, até mesmo, bancar o seu crescimento com recursos próprios.

O gráfico 2, a seguir, apresenta uma comparação entre o volume de Crédito Rural Oficial e o PIB Agrícola. Através desta comparação podemos visualizar a importância do apoio oficial às atividades rurais até a virada da década de 80 .

Observa-se, pelo Gráfico 2, que o Crédito Rural oficial se manteve em volumes muito elevados durante toda a década de 70. $\mathrm{Na}$ realidade, o volume de crédito superava em muito o valor da produção agropecuária. Em 1975, o crédito rural chegou a representar 1,66 do PIB da agropecuária. Na década de 80 , ocorre uma redução do volume de crédito rural oficial e a relação crédito / PIB da agropecuária cai abaixo da unidade. Durante os anos 80 , mantém-se uma relação em torno de 0,5 entre o crédito oficial e o PIB da agropecuária, até que finalmente a relação cai para menos de 0,2 no final da década.

Quando comparamos o crédito com o PIB da agropecuária, estamos deliberadamente incorrendo em uma impropriedade. O PIB se refere apenas ao valor adicionado gerado por uma determinada atividade, enquanto que o crédito diz respeito ao financiamento de insumos e bens intermediários. Ou seja, o financiamento deveria se referir a tudo aquilo que não é valor adicionado. Esta observação, feita por

Gráfico 2

\section{Brasil: Crédito Rural em Relação ao PIB Agrícola}

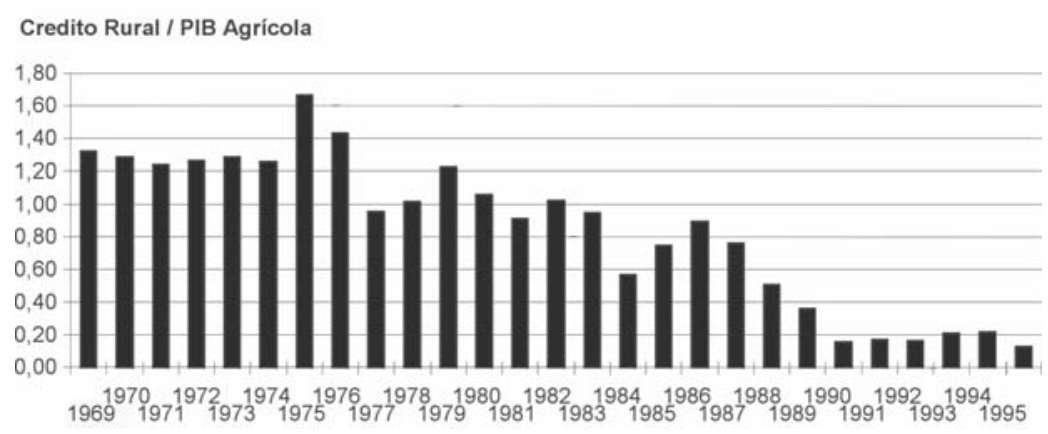

Fonte dos Dados Brutos: Banco Central do Brasil, elaboração do autor.

- ${ }^{9}$ Graziano da Silva (1996) demonstra que os preços internos dos alimentos básicos até que se redu- ziram ao longo da década. O problema maior durante os anos 80 foi a perda de poder de compra - imposta pela política de ajuste econômico. Segundo dados levantados por Graziano da Silva (1996:1330), - o salário mínimo cai a menos da metade entre 1981 e 1990, em termos reais. Nestas condições, os produtores são praticamente empurrados para o mercado externo. 
Munhoz (1982), permanece válida e mostra que, se o valor adicionado gerado pela agropecuária é, historicamente, cada vez menor, o volume de crédito que deveria financiar o consumo intermediário teria que ser cada vez maior. Segundo cálculos realizados por Kageyama (coord.) (1990:121), o consumo intermediário na agricultura estaria próximo de $40 \%$ do Valor Bruto da Produção, o que demonstra que, na realidade, a relação crédito/ PIB estaria subestimando o financiamento concedido a agricultura. O financiamento concedido a agricultura teria uma dimensão muito maior que aquela apresentada muito embora este efeito esteja diminuindo ao longo do tempo.

Em resumo, podemos afirmar que este período de regulação estatal, que vai de meados dos anos 60 até o final dos 80 , contou com instituição de diferentes mecanismos de controle e incentivo ao crescimento setorial. $\mathrm{O}$ volume de recursos à disposição de todas as atividades foi se elevado fazendo com que, inclusive, ocorressem profundas distorções regionais e setoriais. Esta diferenciação no interior do setor agropecuário irá se agravar com a mudança no enfoque dado à participação do Estado na regulação das políticas setoriais.

\section{III - Maturidade e Auto-re- gulação no Complexo Agroin- dustrial}

A redução dos recursos à disposição dos produtores agrícolas e da agroindústria levou a redução das demandas individuais sobre recursos que eram considerados públicos. Os anos 80 trazem uma radical mudança de relacionamento entre o Estado e os grupos de interesses. O enfraquecimento do Estado, seja em termos políticos ou seja no seu poder financiador, abre espaço para aquilo que denominamos anteriormente de Governo de Interesses Privados.

Segundo Lamonier (1994: 15), o esgotamento do crédito subsidiado coincide com a abertura democrática e vai ocorrer uma corrosão do poder da "elite tecnoburocrática" e o surgimento de demandas mais articuladas em novas "arenas relevantes para a feitura de políticas públicas”. Em outras palavras, é o fim das políticas distributivas e o fortalecimento de políticas (auto) regulatórias.

Assim como o processo descrito por Cox, Lowe e Winter (1986) para a Grã-Bretanha, observa-se que, em um primeiro momento, com o peso do Estado mais forte, as políticas agrícolas vão organizando, criando e abrindo a sua gestão para os grupos privados reunidos em tor- no de grupos de pressão. Em um segundo momento, quando o poder financeiro do estado se enfraquece, o poder político destas organizações se reforça, levando a uma situação de auto-regulação.

Não é apenas por ventura que o caso britânico pode ser tomado como exemplo para o Brasil. Os anos 80 marcam um profunda revisão do paradigma do Estado Keynesiano, que tem como motivo de ordem prática a impossibilidade de financiamento das políticas de desenvolvimento. No entanto, existe um outro motivo importante e pouco mencionado para a transição de uma forma de regulação para a outra. Trata-se do crescimento do poder das empresas transnacionais na produção e comércio de produtos agroalimentares. Com o crescimento da internacionalização e do poder das transnacionais diminui o poder e a significância das políticas agrícolas e também, diretamente, na produção agrícola. Esta passa a ser cada vez mais dependente do restante dos sistemas alimentares mundiais.

Outra questão importante é que a combinação da concentração produtiva com o "technology-push" levou a uma imposição de hábitos culturais e formas de consumo que são distintas das formas nacionais ${ }^{10}$. Segundo Allaire e Boyer(1995), os dispositivos institucionais regulatórios que eram de caráter nacional 
passam a ser globais. Um exemplo destas distorções está na sobreposição de dispositivos locais, nacionais e internacionais nas grandes zonas de comércio ${ }^{11}$.

Uma das razões para o fortalecimento das transnacionais está na mudança dos preços relativos no âmbito dos Complexos Agroalimentares. Após um período de alta acelerada do preço das commodities nos anos 70, impulsionadas principalmente pela instabilidade nos mercados financeiros internacionais, os preços das commodities agroalimentares - principalmente aquelas "in natura" - entram em um período de baixa. No entanto, baixa se deve não apenas à diminuição relativa da instabilidade nos mercados financeiros, mas também ao exposto acima: a formação de amplas zonas de livre comércio entre os países. O Gráfico 3 ilustra este movimento.

Observa-se, pelo gráfico acima, que as cotações internacionais das commodities estiveram, nos anos 80, muito abaixo da média histórica dos anos 70. Esta variação acentuada levou ao desincentivo a exportação de produtos "in natura” e ao crescimento da produção de produtos processados por parte dos governos ${ }^{12}$. Como conseqüência desta situação, muitas empresas que realizavam atividades de comercialização de grãos aprofundaram a sua verticalização,

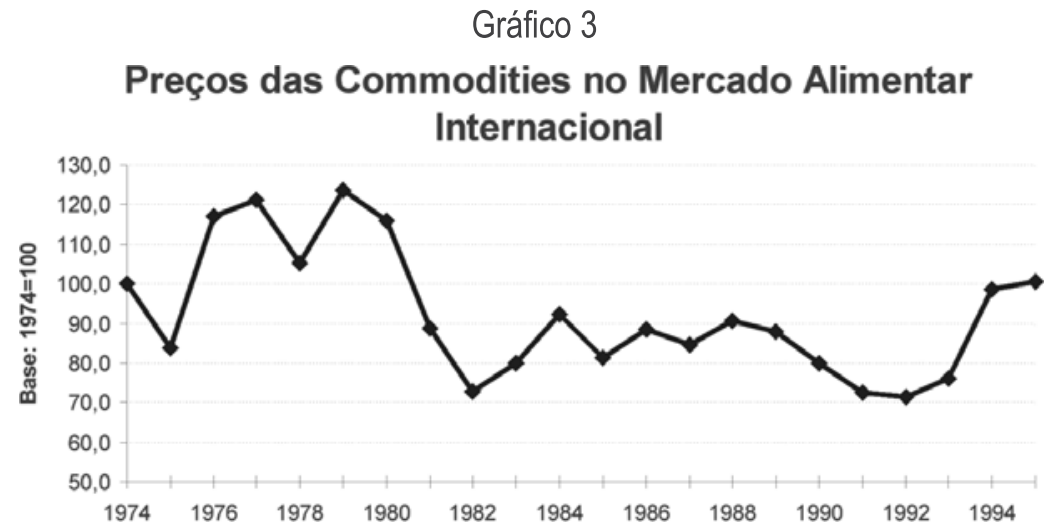

Fonte dos Dados Brutos: The Economist

assumindo parcelas do processamento do produto, visando a exportação ou o mercado interno. $\mathrm{O}$ resultado deste processo é o fortalecimento das firmas processadoras diante de um elo agrícola enfraquecido e desamparado pelas políticas públicas.

No caso brasileiro, esta mudança de enfoque levou a emergência de uma certa auto-regulação na gestão de políticas para os CAIs mais importantes. Vale lembrar que existe um paralelo com o caso britânico apontado anteriormente, mas o Brasil tem características muito distintas dos países centrais. Tomando-se os principais complexos em atividade no agro brasileiro, foi possível constatar a seguinte situação:

No suco cítrico, reduz-se o papel do Estado na concessão de be- nefícios às exportações. Os preços da caixa de laranja, que eram determinados através de negociações tripartites com o aval do governo, passam a ser estabelecidos diretamente por uma fórmula definida a partir da cotação do suco no mercado internacional (contrato de participação). Ao mesmo tempo, o segmento logra definir alguns parâmetros básicos de negociação com relação à qualidade da matéria-prima ${ }^{13}$.

Na produção de aves, generalizam-se os contratos de quaseintegração e aumenta a participação das indústrias processadoras no financiamento das atividades agrícolas. Parte importante da pesquisa para adaptação das aves e mesmo desenvolvimento de novas linhagens é assumida pelas empresas. O Estado se retira também da logística de suprimentos de matéria-

- ${ }^{11}$ Esta questão, levantada por Allaire e Boyer, leva a reflexão da articulação de novas formas de - regulação, de caráter local ou setorial . Ver a este respeito Allaire, G. Boyer, R. (1995)

- ${ }^{12}$ Conforme Belik (1992)

- ${ }^{13}$ Tavares (1996).
} 
prima para os criadores, o que leva ao deslocamento de parte das criações e abatedouros para as regiões de produção agrícola. Neste contexto, há um fortalecimento das representações dos diversos elos da cadeia produtiva: fornecedores de pintos de corte, avicultores, abatedouros e exportadores ${ }^{14}$.

Na cana-de-açúcar, vai ocorrer a desativação gradativa de todo sistema de apoio que tinha como base o Estado em favor dos produtores agrícolas e industriais. Neste sentido, a pesquisa, a assistência técnica e a regulação de cotas e preços de exportação, assim como os preços praticados internamente, passam a ser definidos por um órgão colegiado de produtores com a discreta participação do governo. Esta maior autonomia dos produtores leva ao abandono e mudança de prioridades com relação a determinadas políticas como, por exemplo, o Proálcool.

No complexo soja, vai ocorrer uma retirada gradativa do Estado com a perda da sua capacidade de financiamento. O sistema de Empréstimos do Governo Federal perde espaço para determinadas práticas privadas de financiamento de capital de giro. No caso das Aquisições do Governo Federal, que tradicionalmente permitiram a expansão da soja para regiões de fronteira, observa-se o mesmo quadro. Há uma redução do peso do Estado no financiamento, que é preenchido diretamente pelos agentes privados que, por sua vez, passam a estar cada vez mais presentes nas regiões de fronteira ${ }^{15}$.

No café, o quadro é semelhante. $\mathrm{O}$ antigo órgão de coordenação e intervenção no mercado, o IBC, vai perdendo densidade até que finalmente é desativado em 1989. Por outro lado, a organização precária dos produtores permite levar algumas frentes em comum com relação a preços e políticas de estoques, apesar dos problemas com relação à sobrecapacidade instalada e da baixa qualidade da matériaprima $^{16}$.

No caso do complexo leite e laticínios, há uma mudança nos controles públicos em direção a uma crescente auto-regulação. Os diferentes grupos de interesses, como aqueles estabelecidos nas associações de produtores de leite, nas associações industriais de produção de queijos e na indústria de alimentos em geral, procuraram estabelecer uma agenda comum através da sistemática de câmaras setoriais. Ao mesmo tempo, o Estado se retrai nas suas compras para programas assistenciais e os preços e margens passam a ser cada vez mais um assunto interno dos próprios produtores em suas reivindicações junto aos órgãos de controle $^{17}$.

No setor de trigo e massas, ocorrem mudanças importantes. Ao final do anos 60, através de decreto lei, cria-se um aparato estatal que irá dar sustentação financeira e institucional à política tritícola. No entanto, já no início dos anos 80 , o Estado começa a se retirar paulatinamente do segmento reduzindo drasticamente o subsídio ao consumo. Ao mesmo tempo, emergem nas negociações sobre cotas e preços nos grupos de interesses ligados não apenas à indústria moageira e aos produtores e cooperativas, mas também àqueles representando os produtores de milho, os fabricantes de massas e até mesmo os transportadores do cereal $^{18}$.

Em outros importantes CAIs vai ocorrer a mesma situação. Há um esgotamento da capacidade financeira do Estado e um abandono gradativo do seu poder de regulação. A falta de financiamentos para o complexo papel e celulose ou mesmo a impossibilidade do Banco do Brasil de bancar a política do trigo, levam a emergência de uma regulação privada nos setores assim como ocorre com a carne bovina, borracha natural, algodão e outros. Ocorre também, curiosa-

- ${ }^{15}$ Segundo dados da CFP, depois CONAB, o recorde de AGFs se deu na safra 1986/87 em que 23\%

- da safra de grãos foi financiada pelo governo. Nesta mesma safra, o EGF atingiu $18 \%$ da produção

- de grãos. Após esta extraordinária safra, o volume de AGFs se reduziu a praticamente zero.

- ${ }^{16}$ Conforme estudo de Farina (1996).

- ${ }^{17}$ Ver a este respeito o esclarecedores trabalhos de Conceição (1994a) e Conceição (1994b).

- ${ }^{18}$ Conforme levantamento realizado por Ramalho (1994).
} 
mente, o surgimento de acordos e auto-regulação em segmentos emergentes, onde a presença do Estado era reduzida, como é o caso das frutas de mesa e flores.

A realização de Câmaras Setoriais é um elemento emblemático desta fase. Ao final da década de 80 , inicia-se a discussão de determinados temas setoriais utilizando-se de mecanismos de decisão tripartites em Câmaras Setoriais. Nestas, o governo se comprometia a assumir alguns compromissos em relação a redução de impostos e redução de alíquotas de importação de insumos, e os demais representantes pactuavam toda a administração de políticas para o setor.

Evidentemente, os segmentos mais organizados e mais coesos estiveram muito próximos de um mecanismo de auto-gestão. Considerando-se que a organização de muitos segmentos ainda se baseava em questões "gremiais", de cunho reivindicativo, vai ocorrer um afastamento da gestão das políticas públicas e uma perda de poder regulatório por parte dos mesmos segmentos. Por este motivo, não podemos afirmar que, neste período, vivemos um Governo de Interesses Privados.

Evidentemente, durante esta fase, a preocupação dos governos está em controlar o processo inflacionário. Neste sentido, as políticas agrícolas passam a se subordinar as necessidades colocadas pelo combate a inflação. Ao se retirar gradativamente do manejo e da gestão das políticas agrícolas que ocorria nas arenas decisórias tradicionais, o Estado abre espaço para uma maior presença dos grupos oligopólicos setoriais. É por este motivo que, quando chamado a intervir nas questões internas de gestão setorial (por questões relativas a preços e margens, importações etc.), os governos acabavam por se submeter ao poder de oligopólio dos grandes grupos econômicos.

\section{IV - Novos Desafios na Ges- tão de Políticas para o Campo}

Analisando o desenvolvimento da gestão da política agrícola na Grã-Bretanha na década de 80 , Marsden, Flynn \& Ward (1994) descrevem a intervenção do Estado em dois eventos que alteraram bastante a relação entre o Estado e os produtores rurais. Trata-se da questão da "síndrome da vaca louca" e da salmonela nos ovos - dois problemas sanitários que atingiram a Grã-Bretanha no final da década de 80. Observou-se que, em ambos os casos, a atuação do Estado foi modesta não chegando a cumprir com as suas funções tradicionais de fiscalização e controle. Segundo os autores, os esquemas corporatistas tendem a desaparecer na medida em que aumenta a influência isolada de associações ou de elos isolados da cadeia, como a distribuição, por exemplo.

Assim como na Grã-Bretanha, a crise fiscal no Brasil leva ao quase abandono, inclusive, dos papéis tradicionais reservados ao Estado na gestão do agro. Como vimos anteriormente (Gráfico 1), o volume de crédito oficial atinge os seus níveis mais baixos em 1990 e 1991. Ao mesmo tempo, vai ocorrer um verdadeiro "desmonte" das estruturas de pesquisa, assistência técnica e comercialização para a agricultura. Neste contexto de crescente auto-regulação, os interesses constituídos e consolidados são submetidos a novas mudanças estruturais que resultam em uma nova dos esquemas de governança setoriais.

Os novos fatores que irão influenciar no desarranjo das consolidadas formas de governança nos anos 90, são, no plano mais geral, a abertura comercial, a formação do Mercosul e o aprofundamento da crise fiscal do Estado. No plano específico, temos o crescimento do peso do elo da distribuição na cadeia e a entrada de novas firmas transnacionais no comércio e processamento de produtos agropecuários. Todos estes fatores nos permitem afirmar que o CAI brasileiro passa a se submeter a uma crescente desregulação a partir dos anos 90 .

Com a retirada gradativa do Estado no financiamento da agricultura, estabelecem-se novas formas de financiamento com pouca ou nenhuma relação com o Crédito Rural. O antigo papel orientador da modernização estabelecido pelo Crédito Rural tradicional é substituído por relações privadas entre os diferentes agentes do elo da cadeia produtiva. Uma 


\section{Gráfico 4}

\section{Brasil: Relação entre Empréstimos para o setor rural e os créditos oficiaisl}

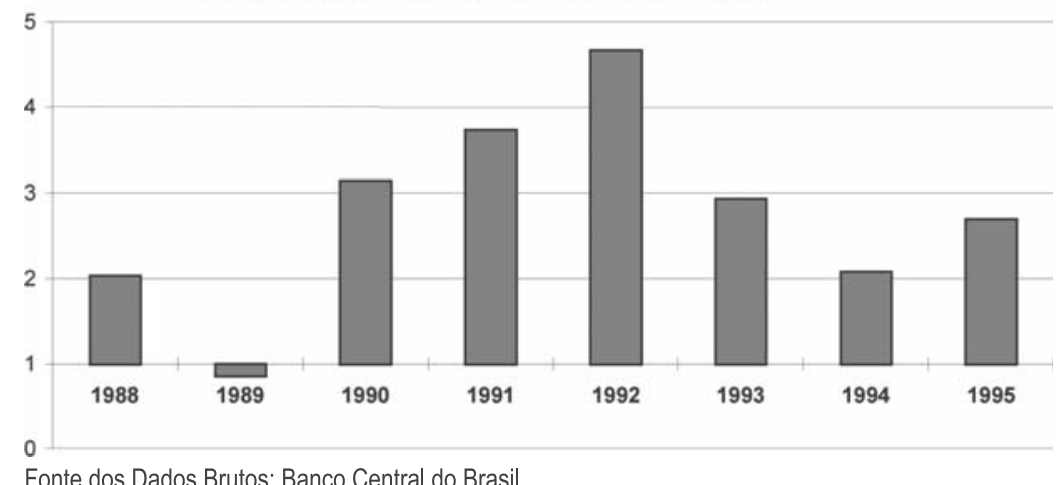

Fonte dos Dados Brutos: Banco Central do Brasil

das questões que surgem freqüentemente nos debates sobre política agrícola brasileira diz respeito à manutenção dos níveis de produção de grãos no final dos anos 80 , a despeito da mudança de prioridades com relação ao do crédito oficial. Para entendermos melhor o problema, o caminho deveria ser o de traçar o crescimento das formas alternativas de financiamento à agricultura naquele período.

O Gráfico 3 apresenta a relação entre os números do Crédito Rural Oficial e os saldos dos empréstimos do sistema financeiro voltados para o setor rural ${ }^{19}$. Observa-se pelo gráfico o enorme crescimento dos empréstimos ao setor rural em relação ao crédito oficial. O Gráfico 3 nos apresenta uma evidência de como os agentes financeiros foram preenchendo o espaço deixado pelo governo na liberação do crédito. Em 1992, por exemplo, o crédito que passou pelo sistema financeiro voltado para a atividade agropecuária representou 1,46 vezes o crédito fornecido pelo SNCR. Este movimento levou a manutenção das atividades agropecuárias em bases precárias. Este "multiplicador" do crédito oficial não tem um comportamento definido dependendo da maior ou menor liquidez da economia, da taxa de juros de mercado e das expectativas dos agricultores.

Na realidade, o Gráfico 4 apresenta somente alguns elementos do crédito para a agropecuária nos anos 90. Tratam-se apenas das operações realizadas através do sistema financeiro. Agregue-se a isto uma crescente desintermediação que leva ao financiamento dos agentes produtivos através de es- quemas de quase-integração, venda antecipada ou até mesmo agiotagem, no pior dos casos. Dentro destas inúmeras categorias está a negociação de antecipações através da venda futura da safra em bolsas de mercadorias.

Tomando-se a BM\&F, a mais importante bolsa negociadora de commodities do país, observamos que o crescimento dos contratos de venda futura foi enorme. Muitos contratos negociados na $\mathrm{BM} \& \mathrm{~F}$ já eram realizados em outras bolsas, portanto não há como medir o seu crescimento recente. No entanto, vale dizer que atualmente a bolsa paulista é a quarta maior do mundo em volume de negócios com um número de contratos agrícolas equivalente a $240 \mathrm{mil}$ por ano. Segundo o gerente de mercados agrícolas da $\mathrm{BM} \& \mathrm{~F}$, atualmente "os negócios com futuros com café equivalem à metade da safra brasileira e os de boi gordo, a $15 \%$ do rebanho nacional" 20 .

O resultado desta estratégia de "livre mercado" para a agropecuária é que com isto se deixa desamparada uma parcela de produtores não articulados em torno dos interesses mais organizados do complexo. Em outras palavras, vai ocorrer um desgaste nas tradicionais alianças que tinham como base o enorme feixe de interesses que, por sua vez, permitiam governança setorial. Este desgaste é reforçado pela instabilidade decorrente da rápida abertura comerci-

\footnotetext{
- ${ }^{19}$ Os números foram comparados em dólares ao câmbio médio do ano (câmbio oficial de venda).

- ${ }^{20}$ Entrevista de Felix Schouchana ao jornal Gazeta Mercantil, 22/10/96, pag. B-16.
} 
al pela qual passou o país nos últimos anos. Para ilustrar, a tarifa aduaneira média para importação de alimentos estava em torno de $85 \%$ em 1988, sendo que hoje esta se encontra em torno de apenas $22 \%$. O algodão, que tinha uma tarifa de $38 \%$, passa para zero pontos percentuais já em 1990, para ficarmos apenas nestes exemplos ${ }^{21}$.

A entrada do país no Mercosul, acompanhada por uma política de apreciação do câmbio, faz com que determinados setores da agroindústria sofram uma profunda mudança. A arena de decisões deixa de ser "paroquial" e passa a envolver uma abrangência muito maior, marcada pela multiciplidade de atores e pela multi-sintonia das políticas nacionais. $\mathrm{O}$ ambiente torna-se, assim, favorável ao desenvolvimento das empresas transnacionais no comércio e transformação de produtos da agropecuária. Ironicamente, observa-se que a política agrícola continua a se submeter às necessidades ditadas pela política anti-nflacionária dos Governos. No entanto, desta vez, sem os mecanismos de proteção de mercado utilizados na década passada.

Para as firmas multinacionais, acostumadas a operar em escala mundial, o novo quadro favorece a expansão dos seus negócios. $\mathrm{Na}$ realidade, desde a segunda metade dos anos 80, o movimento de fusões e aquisições leva a uma mudança radical no quadro da indústria de alimentos brasileira. Importantes segmentos da indústria brasileira são praticamente desnacionalizados na virada da década. Este não é um movimento isolado, que ocorre apenas nas fragilizadas economias da periferia, mas sim uma "onda" de reestruturação que atinge a indústria dos países centrais e que chega ao Brasil até mesmo já enfraquecida (Belik, 1994).

A emergência do varejo como elo fortalecido da cadeia agroindustrial tem o mesmo efeito do anterior. De acordo com o novo paradigma produtivo de flexibilização e segmentação, as atividades mais bem estruturadas e mais dinâmicas têm condições de sair na frente e abocanhar parcelas maiores do valor adicionado da produção agroindustrial. A falência do antigo sistema de aprovisionamento faz com que os pioneiros no fornecimento e gerenciamento de sistemas "just-in-time" tenham enormes sobrelucros e imponham elevadas barreiras aos competidores tradicionais ${ }^{22}$.

Os motivos apontados acima demonstram que o novo ambiente competitivo não favorece a manutenção de arranjos neocorporatistas. A desregulação estatal leva à desagregação de determinados grupos de interesses, que muitas vezes passam a ser obsoletos no novo cenário produtivo setorial. Tomando-se os fatores que favorecem no surgimento do corporatismo mencionados por Cawson (1986), podemos avaliar as mudanças no padrão de governança na agropecuária brasileira.

Segundo Cawson (1986) existem seis fatores que influenciam no aparecimento ou desaparecimento do corporatismo em uma sociedade. A análise deste fatores nos permite entender os motivos da passagem de um período para o outro nesta periodização sobre as formas de intervenção no agro brasileiro. Estes elementos históricos são aqueles que se seguem:

1) Natureza do produto, ou seja: as suas características de perecibilidade, suas possibilidades de padronização e homogeneização.

2) O peso de firmas multiproduto no âmbito do complexo. Supõe-se que uma grande participação de firmas multiprodutos iniba a constituição de interesses já que estas firmas estariam mais dispostas a disputar posições em outros mercados que lutar por políticas únicas, lado a lado com seus concorrentes e fornecedores.

3) A presença de empresas multinacionais. Estas têm interesses específicos que, em certos casos, não levam a formação de frentes comuns com empresas locais.

4) A competitividade internacional das firmas locais. Este fator leva a uma inibição da ação coletiva em determinados setores.

\footnotetext{
- ${ }^{21}$ Dados do DECEX/SECEX - Ministério de Indústria e Comércio.

- ${ }^{22}$ Ver a este respeito Green \& Schaller (1996).
} 
Como os "foruns" decisórios não passam pelo governo e nem pelos poderes locais, não há propensão à associação.

5) A maturidade tecnológica do setor. Este é um fator decisivo na busca do associativismo, uma vez que os setores menos maduros necessitam de programas de desenvolvimento e uma maior intervenção do Estado.

6) O grau de concentração econômica dentro do setor também é decisivo. Em um ambiente de pequenas empresas dispersas em um mercado atomizado, o grau de organização do setor tende a ser reduzido pela incapacidade de se obter uma agenda comum de desenvolvimento.

De modo geral, o aumento do grau de concentração, o maior peso das firmas transnacionais - que em grande parte são multiproduto e a maior competitividade e maturidade tecnológica do setor levam a um distanciamento cada vez maior das práticas neocorporativistas de governança. Dependendo da natureza do produto gerado no CAI a ocorrência destas práticas vai ser maior ou menor.

São vários os exemplos que podemos citar para o caso brasileiro, em que os fatores de desagregação de uma incipiente autoregulação mencionados acima levaram a situação de conflito aberto de interesses no âmbito do setores agroindustriais. Trata-se de uma nova situação em que os grupos de interesses tradicionais se desfazem em nome de benefícios, vantagens ou ganhos de fatias de mercados isolados para firmas isoladas ou pequenos grupos de produtores. Respeitando-se as diferenças históricas e as características de mercado em setores como o do café, açúcar e álcool, carne bovina, trigo, massas e biscoitos e suco de laranja, entre outros, em todos estes casos está ocorrendo uma profunda depuração nas formas de operação. Em todos estes exemplos o antigo consenso entre os diferentes grupos de interesse praticamente desapareceu.

Em alguns casos, os segmentos mais organizados conseguiram segmentar o seu mercado e se reorganizar obtendo, para tanto, fontes de financiamento e canais de escoamento para os seus produtos. No limite, alguns setores conseguiram estabelecer novos contratos entre as partes instituindo novas práticas de atuação. Normalmente, setores que já possuíam uma certa auto-regulação tiveram mais sucesso que setores totalmente desorganizados.

Neste contexto, podemos vislumbrar um quadro de reacomodação para a gestão dos CAIs no Brasil. O Estado está perdendo a sua capacidade de regulação sobre a produção agropecuária. Do ponto de vista orçamentário e fiscal, esta pode ser uma conquista para a gestão das contas públicas. Mas, do ponto de vista social e levando-se em conta que não existe um arcabouço institucional que possa absorver os interesses mais frágeis, ou mesmo organize demandas dis- persas, este novo contexto é perverso e desagregador.

\section{$V-$ Conclusões}

Neste trabalho, analisamos a evolução da intervenção do Estado na gestão das políticas para o Complexo Agroindustrial no Brasil. Tomando-se a abordagem neocorporatista como referência, observamos que a gestão das políticas passou por três momentos distintos: regulação estatal, autoregulação e desregulação.

Em primeiro momento, o Estado estabelece uma via de dupla mão com os interesses constituídos. Este é período de modernização acelerada e constituição dos CAIs. Através de arranjos de fundo neocorporatista logra-se implementar e desenvolver importantes setores da agropecuária no Brasil. $\mathrm{Na}$ década de 80 , com a paulatina perda de capacidade financeira e administrativa por parte do Estado, os setores mais consolidados conseguem estabelecer uma espécie incipiente de auto-regulação. Esta nova forma de atuação dos interesses constituídos passa a determinar margens, quantidades, rotinas de distribuição e divisão do mercado entre os diferentes atores de cada CAI. A virada da década de 80 leva a uma mudança radical nestes procedimentos introduzindo novos elementos internos e externos ao planejamento de políticas para os CAIs. 
Esta fase recente, que estamos denominando de desregulação, exige uma nova abordagem para o mapeamento dos elementos básicos para o planejamento do desenvolvimento dos CAIs. Não há dúvida que sem fundos para o financiamento dos produtores agrícolas e industriais e sem recursos para operar estoques reguladores, as possibilidades dos governos de direcionar e intervir em aspectos básicos que se relacionam com o agro ficam reduzidas. Por outro lado, com a abertura comercial, formação de blocos econômicos regionais e com a estabilidade da economia, as arenas de decisão se multiplicam exigindo um maior acompanhamento de outras variáveis que não aquelas que passam pelos gabinetes do governo.

Não há dúvida que as possibilidades de direcionar o desenvolvimento e corrigir distorções de crescimento tendem a diminuir com o aprofundamento da desregulação. No entanto, ainda é possível retomar alguns instrumentos de política pública - que são inerentes ao caráter do Estado - de forma a recolocar certas prioridades públicas no desenvolvimento dos setores da agropecuária no Brasil.

\section{VI - Referências Bibliográfi- cas}

Accarini, J. H. (1987) Economia Rural e Desenvolvimento: Reflexões sobre o Caso Brasileiro. Petrópolis: Vozes
Allaire, G. Boyer, R. (1995) Régulations et Conventions dans l'Agriculture et les IAA In: Allaire, G. Boyer, R. (editores) La Grande Transformation de l'Agriculture. Paris: INRA/ Econômica, pp. 9-32.

Baer, W. (1995) A Economia Brasileira. São Paulo: Nobel

Belik, W. (1992) Agroindústria Processadora e Política Econômica. Tese de Doutoramento. Campinas: IE/Unicamp. . (1994) The Food Industry in Brazil: Towards a Restructuring? Londres, Inglaterra: ILAS/ University of London (Research Papers $\left.n^{\circ} .35\right)$

Bertrand, J. P. (1982) Systèmes AgroAlimentaires: Méthodes d'Analyse, Division du Travail, Modes d'Organization et Stratégies. Séminaire de Doctorat - INRA / Université de Paris I - Panthéon - Sorbonne.

Brousseau, E. (1996) De la Science du Marché à l'Analyse Économique et Formes de Coordination". Paris: Cahiers Français, ${ }^{\circ}$. 272 pp. 54-63.

Cawson, A. (1985) Varieties of Corporatism: The importance of Meso-Level of Interest Intermediation In: Cawson, A. Organized interest and State - Studies in Meso-Corporatism. Edited by Alan Cawson. London: Sage Publications.

Cawson (1986) Corporatism and Political Theory. Oxford: Basil Blackwell

Cox, Lowe \& Winter (1986) From State Direction to Self Regulation: The Historical Development Of Corporatism In British Agriculture. Rev Policy and Po- litics. 14 (4). Outubro de 1986, pp. 475-491.

Conceição, S. V. (1994) Les Barrières à la Diffusion de la Marque: Le Cas du Marché Brésilien des Produits Laitiers Frais Sous Marque. Rev. Economie et Gestion Agro-alimentaire, Cergy, França, no.31, abril, pp.5-27. (1994). Analyse Stratégique Comparée des Firmes Laitières au Brésil. Cergy, França, Rev. Economie et Gestion Agro-Alimentaire, $\mathrm{n}^{\mathrm{o}} .33$, outubro, pp.511.

Farina, E.M.M.Q. (1996) Reflexões sobre Desregulamentação e Sistemas Agroalimentares. São Paulo: FEA/USP. Tese de Livre-Docência.

Graziano da Silva, J. (1982) A Modernização Dolorosa. Rio de Janeiro: Zahar.

(1996) A Nova Dinâmica da Agricultura Brasileira. Campinas: Instituto de Economia/Unicamp.

Green, R. ; Schaller, B. (1996) Rationalisation Comerciale et Mise en Marche de Produits Alimentaires. Paris: INRA

Goldin, I. \& Castro de Rezende, G. (1993) A Agricultura Brasileira na Década de 80 ; Crescimento numa Economia em Crise. Rio de Janeiro: IPEA (Série IPEA 138).

Kageyama, A. (coord.) (1990) O Novo Padrão Agrícola Brasileiro: Do Complexo Rural aos Complexos Agroindustriais. In: Delgado, G. C. et al. (org.) Agricultura e Políticas Públicas. Rio de janeiro: IPEA (Série IPEA 127)

Lamounier, B. (coord.) (1994) Determinantes Políticos da Política Agrícola: Um Estudo dos Atores, 
Demandas e Mecanismos de Decisão. Brasília: IPEA Estudos de Política Agrícola 4).

Linhares, M.Y.L. (1979) História Política do Abastecimento (19181974) Brasília: Binagri - Ministério da Agricultura

Martins, S. S. (1996) Cadeias Produtivas do Frango e do Ovo: Avanços Tecnológicos e sua Apropriação. Tese de Doutoramento. São Paulo: EAESP/FVG.

Marsden, T; Flynn, A \& Ward, N. (1994) Food Regulation in Britain: A National System in an International Context In: Bonanno, A.; Busch, L.; Freedland, W; Gouveia, L. \& Mignone, E. (1994). From Columbus to ConAgra Lawrence: University Press of Kansas, pp. 105-124.

Mueller, C. (1982) Formulação de Políticas Agrícolas. Rev. Ec. Pol. 2(1), jan.- mar. 1982. São Paulo: Brasiliense. pp. 89-102.

Munhoz, D. (1982) Agricultura: Uma Defesa dos Subsídios. Petrópolis: Vozes

Offe, C. (1989) A Atribuição de "Status" Público aos Grupos de Interesse In: Offe, C. Capitalismo Desorganizado. São Paulo: Brasiliense

Pinto, L. C. G. (1981) Notas sobre a política de Crédito. Campinas: Unicamp (Convênio Fundação Ford / Unicamp)

Ramalho, A. (1994) Complexo Agroindustrial, Grupos de Interesses e Políticas Públicas: O Caso do Trigo no Brasil. Tese de Doutoramento. Campinas: IE/UNICAMP.

Schmitter, P. (1985) Neocorporatismo y Estado. REIS - Revista Española de Sociologia, Madri, $\mathrm{n}^{\mathrm{o}} .31, \mathrm{pp} .47-78$
Soto, F. (1992) Da Indústria do Papel ao Complexo Florestal: O Caminho do Corporatismo Tradicional ao Neocorporatismo. Tese de Doutoramento. Campinas: IE/ Unicamp.

Streeck, W. \& Schmitter, P. (1985) Private Interest Government Beyond Market and State. Londres: SAGE

Tavares, E.L.A. (1996) Estratégias Competitivas: O Caso da Indústria Citrícola Paulista. Dissertação de Mestrado. Campinas: IE/ UNICAMP.

World Bank (1982) Brazil: A Review of Agricultural Policies. Washington: The World Bank ( A World Bank Study) 